\title{
Correction: A Direct-to-Public Peer Support Program (Big White Wall) Versus Web-Based Information to Aid the Self-management of Depression and Anxiety: Results and Challenges of an Automated Randomized Controlled Trial
}

Richard Morriss ${ }^{1}, \mathrm{MD}$; Catherine Kaylor-Hughes ${ }^{2}, \mathrm{PhD}$; Matthew Rawsthorne ${ }^{1}$, BA; Neil Coulson ${ }^{3}$, PhD; Sandra Simpson $^{4}$, BSc; Boliang Guo ${ }^{1}, \mathrm{PhD}$; Marilyn James ${ }^{3}$, PhD; James Lathe ${ }^{5}$, MSc; Paul Moran ${ }^{6}$, PhD; Laila J Tata ${ }^{3}$, $\mathrm{PhD}$; Laura Williams ${ }^{1}, \mathrm{PhD}$

\footnotetext{
${ }^{1}$ Institute of Mental Health, University of Nottingham, Nottingham, United Kingdom

${ }^{2}$ Department of General Practice, University of Melbourne, Melbourne, United Kingdom

${ }^{3}$ School of Medicine, University of Nottingham, Nottingham, United Kingdom

${ }^{4}$ Research Delivery Team, Nottinghamshire Healthcare NHS Foundation Trust, Nottingham, United Kingdom

${ }^{5}$ Centre for Longitudinal Studies, University College London, London, United Kingdom

${ }^{6}$ School of Medicine, University of Bristol, Bristol, United Kingdom
}

Corresponding Author:

Richard Morriss, MD

Institute of Mental Health

University of Nottingham

Jubilee Campus

Triumph Road

Nottingham, NG7 2TU

United Kingdom

Phone: 441158230427

Email: richard.morriss@nottingham.ac.uk

\section{Related Article:}

Correction of: http://jmir.org/2021/4/e23487

(J Med Internet Res 2021;23(7):e31543) doi: 10.2196/31543

In "A Direct-to-Public Peer Support Program (Big White Wall) Versus Web-Based Information to Aid the Self-management of Depression and Anxiety: Results and Challenges of an Automated Randomized Controlled Trial" (J Med Internet Res 2021;23(4):e23487), one error was noted.

Due to a system error, the name of one author, Laila J Tata, was replaced with the name of another author on the paper, Laura Williams. In the originally published paper, the order of authors was listed as follows:

Richard Morriss, Catherine Kaylor-Hughes, Matthew Rawsthorne, Neil Coulson, Sandra Simpson, Boliang Guo, Marilyn James, James Lathe, Paul Moran, Laura Williams, Laura Williams

This has been corrected to:
Richard Morriss, Catherine Kaylor-Hughes, Matthew Rawsthorne, Neil Coulson, Sandra Simpson, Boliang Guo, Marilyn James, James Lathe, Paul Moran, Laila J Tata, Laura Williams

In the originally published paper, the ORCID of author Laura Williams was incorrectly published as follows:

0000-0002-6404-8658

This has been corrected to:

0000-0001-6296-6677

The correction will appear in the online version of the paper on the JMIR Publications website on July 12, 2021, together with the publication of this correction notice. Because this was made after submission to PubMed, PubMed Central, and other full-text repositories, the corrected article has also been resubmitted to those repositories. 
This is a non-peer-reviewed article. Submitted 24.06.21; accepted 28.06.21; published 13.07.21.

Please cite as:

Morriss R, Kaylor-Hughes C, Rawsthorne M, Coulson N, Simpson S, Guo B, James M, Lathe J, Moran P, Tata LJ, Williams L

Correction: A Direct-to-Public Peer Support Program (Big White Wall) Versus Web-Based Information to Aid the Self-management

of Depression and Anxiety: Results and Challenges of an Automated Randomized Controlled Trial

J Med Internet Res 2021;23(7):e31543

URL: https://www.jmir.org/2021/7/e31543

doi: $10.2196 / 31543$

PMID: $\underline{34255667}$

CRichard Morriss, Catherine Kaylor-Hughes, Matthew Rawsthorne, Neil Coulson, Sandra Simpson, Boliang Guo, Marilyn James, James Lathe, Paul Moran, Laila J Tata, Laura Williams. Originally published in the Journal of Medical Internet Research (https://www.jmir.org), 13.07.2021. This is an open-access article distributed under the terms of the Creative Commons Attribution License (https://creativecommons.org/licenses/by/4.0/), which permits unrestricted use, distribution, and reproduction in any medium, provided the original work, first published in the Journal of Medical Internet Research, is properly cited. The complete bibliographic information, a link to the original publication on https://www.jmir.org/, as well as this copyright and license information must be included. 